\title{
Новая интерпретация тектоники фоидолитового комплекса Хибин и ресурсный потенциал фосфатов
}

\section{Жиров Д.В.}

Геологический институт КНЦРАН, Anamumb, zhirov@geoksc.apatity.ru

Аннотация. Для Хибинского щелочного плутона рассмотрены новые данные по тектонике рудовмещающего комплекса фоидолитов. Предложенная интерпретация расширяет перспективы прироста запасов в нетрадиционных местах локализации руд. Для восточной части Хибинского массива дана предварительная оценка прогнозных ресурсов.

Ключевые слова: тектоника, вязкопластический, апатит, руда, месторождение, разлом, поисковая модель.

\section{New interpretation of the Khibiny foidolite complex tectonics and resource potential of phosphates}

\author{
Zhirov D.V. \\ Geological institute KSC RAS, Apatity,zhirov@geoksc.apatity.ru
}

\begin{abstract}
New data on the tectonics of the ore-hosting foidolite complex in the Khibiny alkaline pluton were studied. The proposed interpretation expands the prospect for the resource growth in unconventional ore localities. A preliminary resource forecast was provided for the eastern part of the Khibiny massif.
\end{abstract}

Key words: tectonics, viscoelastic, apatite, ore, deposit, fault, prospecting model.

\section{Введение}

Хибинская группа комплексных апатит-нефелиновых месторождений является уникальным сырьевым объектом, как по объёмам, так и по качеству. В отличие от осадочных фосфатов во фторапатите практически нет вредных для сельского хозяйства примесей (кадмия и др. тяжёлых и радиоактивных металлов). Кировский филиал АО «Апатит» (Группа «ФосАгро») ежегодно производит порядка 1 млн. т нефелинового и 9-10 млн. т высококачественного апатитового концентрата с содержанием $\mathrm{P}_{2} \mathrm{O}_{5}$ не менее 37.5 \%. Этот уровень обеспечивается добычей 33-38 млн. т руды на 3-х рудниках: Объединённом Кировском (ОКР), Расвумчоррском (РР) и Восточном (ВР) рудниках. Ещё порядка 1.1-1.2 млн. т апатитового концентрата (4.5-5.5 млн. т руды) производит АО СЗФК (Группа «Акрон»). За более чем 90-летний период эксплуатации хибинских месторождений добыто порядка 1.6 млрд. т руды (более 330 млн. т $\mathrm{P}_{2} \mathrm{O}_{5}$ ), остаток запасов и ресурсов в максимальном расчётном варианте составляет около 2.2 млрд. т (примерно 370 млн. т $\mathrm{P}_{2} \mathrm{O}_{5}$ ) со средним содержанием $\mathrm{P}_{2} \mathrm{O}_{5}$ в рудах порядка 14-16 \%. Из приведённых цифр следует, что в недрах осталось чуть более половины от всего разведанного и оценённого объёма, однако, реальное состояние не столь радужно. К настоящему времени остро проявились проблемы с сырьевой базой, ухудшающие финансовоэкономические показатели предприятия:

- истощение легкодоступной (приповерхностной) и наиболее высококачественной / богатой части сырьевой базы апатитовых руд;

- значительное понижение горных работ и обусловленные этим:

- ухудшение горнотехнических условий разработки;

- увеличение инвестиций в горнокапитальные работы и вскрышу;

- возрастание всевозможных рисков и неопределённости исходных для учёта параметров, усложнение администрирования всех технологических процессов;

- у увеличение на глубину и на флангах месторождений изменчивости качественных параметров руд и реологии вмещающих пород;

- ухудшение качества поступающих на переработку руд, в т.ч. по неожиданным причинам (неучтённые факторы качества руды). 
В этих обстоятельствах весьма актуальной смотрится постановка задачи комплексной ревизии традиционной поисковой модели с целью выявления дополнительных, ранее неучтённых факторов контроля оруденения и прогнозных построений по новым перспективным участкам.

\section{Новая интерпретация тектоники фоидолитового комплекса Хибин}

Все месторождения юго-западного рудного поля отнесены ГКЗ к первой, наиболее простой группе сложности, а юго-восточного - ко второй (Методические ..., 2007). Это заключение базируется на почти вековом опыте геологического изучения и эксплуатации апатитовых месторождений. Практически всеми исследователями признаётся рудоконтролирующая роль комплекса фоидолитов (ФК) в целом и уртитов в частности вне зависимости от различий в представлениях о последовательности магматических фаз и характере их взаимоотношений, а также о вкладе в рудогенез магматических и метасоматических процессов. Все промышленные месторождения обнаружены именно в пределах ФК и чётко согласуются с его строением. При этом, интенсивная разрывная тектоника практически не отражается на локализации и строении Ю3 группы месторождений (Кукисвумчорр, Юкспорр, Апатитовый Цирк и Плато Расвумчорр), а для ЮВ группы (Коашва, Ньоркпакх, Олений Ручей) выражается в разлинзовании и разбиении больших пластовых тел на ярусы / отдельные линзы / блоки, сохраняя их положение по простиранию и падению в достаточно узкой зоне. Поисковые обоснования, предполагавшие дифференцированный характер значительных вертикальных смещений вдоль радиальных разломов (Онохин, 1975; Каменев, 1987), в целом не получили явного подтверждения на практике. В западной части Хибинского массива (XM), где согласно реконструкциям Ф.М. Онохина (Онохин, 1975) прогнозировались месторождения в опущенном блоке, промышленно значимых объектов не выявлено, а единственное «слепое» месторождение на глубоких горизонтах (Эвеслогчорр) было обнаружено по падению рудной зоны месторождения Плато Расвумчорр. В связи с этими обстоятельствами действующая поисковая модель предполагает возможности прироста запасов только по падению на глубину и на флангах известных месторождений. Эта концепцию наглядно иллюстрирует крайне низкое текущее соотношение прогнозных ресурсов (264.7 млн. т $\mathrm{P}_{2} \mathrm{O}_{5}$ по $\mathrm{P}_{1}+\mathrm{P}_{2}+\mathrm{P}_{3}$ ) к разведанным запасам (около 840 млн. т $\mathrm{P}_{2} \mathrm{O}_{5}$ по $\mathrm{A}+\mathrm{B}+\mathrm{C}_{1}+\mathrm{C}_{2}$ ) при устоявшейся тенденции отрицательного воспроизводства.

Результаты выполненных в 2010-2019 гг. тектонофизических и структурных исследований позволяют предложить новую интерпретацию тектоники фоидолитового комплекса Хибин, расширяющую перспективы прироста запасов. Она базируется как на хорошо известных, но ранее не использовавшихся в поисковых моделях, так и на новых факторах контроля. К первым относится широкое проявление вязкопластической и пликативной тектоники в рудных телах и в меньшей степени во вмещающих фоидолитах (Жиров, 2019; Zhirov, 2019). Минимум 4 из 7 основных геологических типов руд несут в себе отчётливые признаки вязкопластических и пликативных деформаций
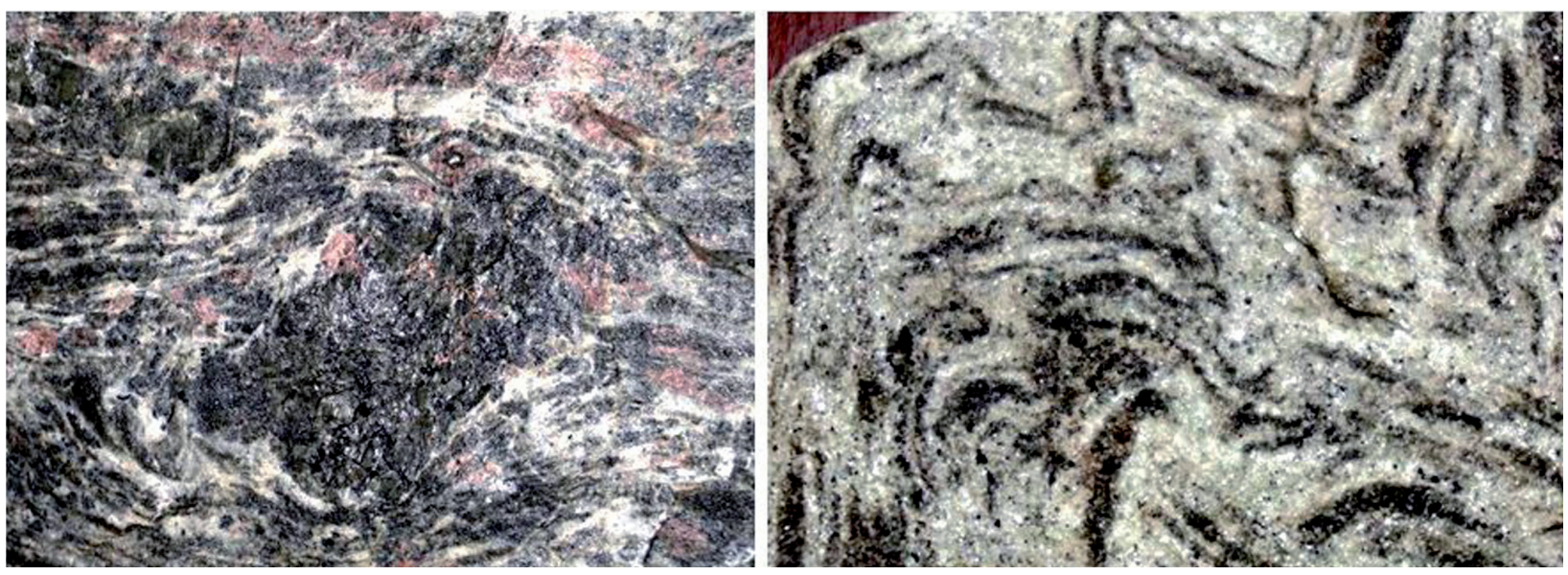

Рис. 1. Примеры вязкопластической и пликативной тектоники в апатит-нефелиновых рудах.

Fig. 1. Examples of viscous flow and plicative tectonics in apatite-nepheline ores. 
(рис. 1). Ранее эти деформации интерпретировались «складками волочения» вследствие надвигания и взбрасывания висячего крыла вмещающих пород (Онохин, 1975) или сложным динамическим взаимодействием несмешивающихся дериватов щелочной магмы в ходе внедрения (Делицын, 1997). По нашим данным это объясняется постмагматическими деформациями в результате интенсивных и многофазных тектонических движений от пластического течения в флюидонасыщенном состоянии на ранних стадиях до реидного в консолидированном состоянии. Руда как бы «выжималась» и «текла» между «жестким» блоком пород висячего крыла и менее «жесткими» породами лежачего крыла. При этом происходило перераспределение и транспорт руд, а также частично вмещающих пород в направлении наверх и/или в структурные ловушки без изменения элементов залегания и существенных преобразований общего строения тел (Жиров, 2019; Zhirov, 2019). В результате формировались мощные выполаживающиеся наплывы в приповерхностной / приконтактовой части ХМ, останцы которых известны в ЮЗ рудном поле: Ийолитовый отрог, Нагорный, восток и запад месторождения Плато Расвумчорр.

Новым неучтённым ранее фактором служит установленное в ходе совместных с ИФЗ РАН исследований значительное постумное протрузивное поднятие интрузива (предположительно на этапе «палеоген - неоген») со срывом краевых приконтактовых частей ХМ и образованием структур «псевдо сброс», в которых смещается вверх лежачее крыло, а висячее остаётся примерно в месте первичного залегания (Жиров и др., 2016; Жиров и др., 2018; Zhirov, Zhirova, 2018). Эти структуры хорошо дешифрируются в рельефе восточной, южной и северной частях Хибин (Zhirov, 2019). Их видимая суммарная вертикальная амплитуда смещения составляет до 400 м, а истинная может быть существенно больше.

Комбинация перечисленных двух факторов с учётом приближения ФК на востоке к границам ХM даёт объективные предпосылки для поиска офсетных залежей апатитовых руд (Жиров, 2019; Zhirov, 2019). В ходе протрузивного поднятия приповерхностные «наплывы» рудовмещающих фоидолитов в краевых частях массива могли оказаться сорванными и законсервированными в месте первичного залегания. Наибольшее количество аргументов и данных в пользу этой версии собрано для района ЮВ склонов гор Суолуайв и Коашкар.

Для понимания особенностей тектоники ФК и её рудоконтролирующей роли также важны новые результаты тектонофизических исследований 2018-2019 гг. Помимо вертикальных смещений нами установлена сдвиговая составляющая в горизонтальном направлении. На основании многочисленных наблюдений и документации прямых геологических взаимоотношений реперных объектов, реконструкций палеостресс состояний и эллипсоидов деформаций методами О.И. Гущенко - Л.А. Сим (Гущенко, 1979; Сим, 1991), Ю.Л. Ребецкого (Ребецкий, 2007), Флинна (Flinn, 1965) выявлена и многократно заверена левосдвиговая зона в рудовмещающем комплексе (рис. 2). Эта зона характерна для всей южной части ФК (для северной части предполагается правосдвиговая зона), но проявляется по-разному для Ю3 и ЮВ рудных полей. Для месторождений восточной части фиксируется интенсивное брекчирование, разлинзование и, вероятно, дублирование разреза, когда нижележащие рудные тела выводятся (надвигаются) и пространственно совмещаются с верхними на одном гипсометрическом уровне, образуя «верхний» и «нижний» рудные ярусы соответственно (месторождения Олений Ручей и Ньоркпахк). Вмещающие породы (уртиты, ийолиты, рисчорриты), разделяющие ярусы, а также руды в основной своей массе приобретают характерные признаки динамометаморфизма: рассланцевание / разгнейсование, брекчирование, плитчатую отдельность и др. Сами рудные тела становятся сильно тектонизированными, фрагментированными / разлинзованными и брекчированными. В то же время тектонические преобразования месторождений ЮЗ рудного поля проходят внутри рудных тел, практически не нарушая их целостность, но привнося многочисленные проявления сдвиговых деформаций, в том числе следы пликативного и вязкопластического течения, срывы, структуры вращения и т.п. Многочисленные признаки преимущественно левых сдвигов установлены во всех месторождениях южной части Хибин и характеризуют как вязкопластическое, так и хрупкое состояния, что даёт нам основания считать тектонические процессы, вызывающие эти деформации, длительными и унаследованными. 


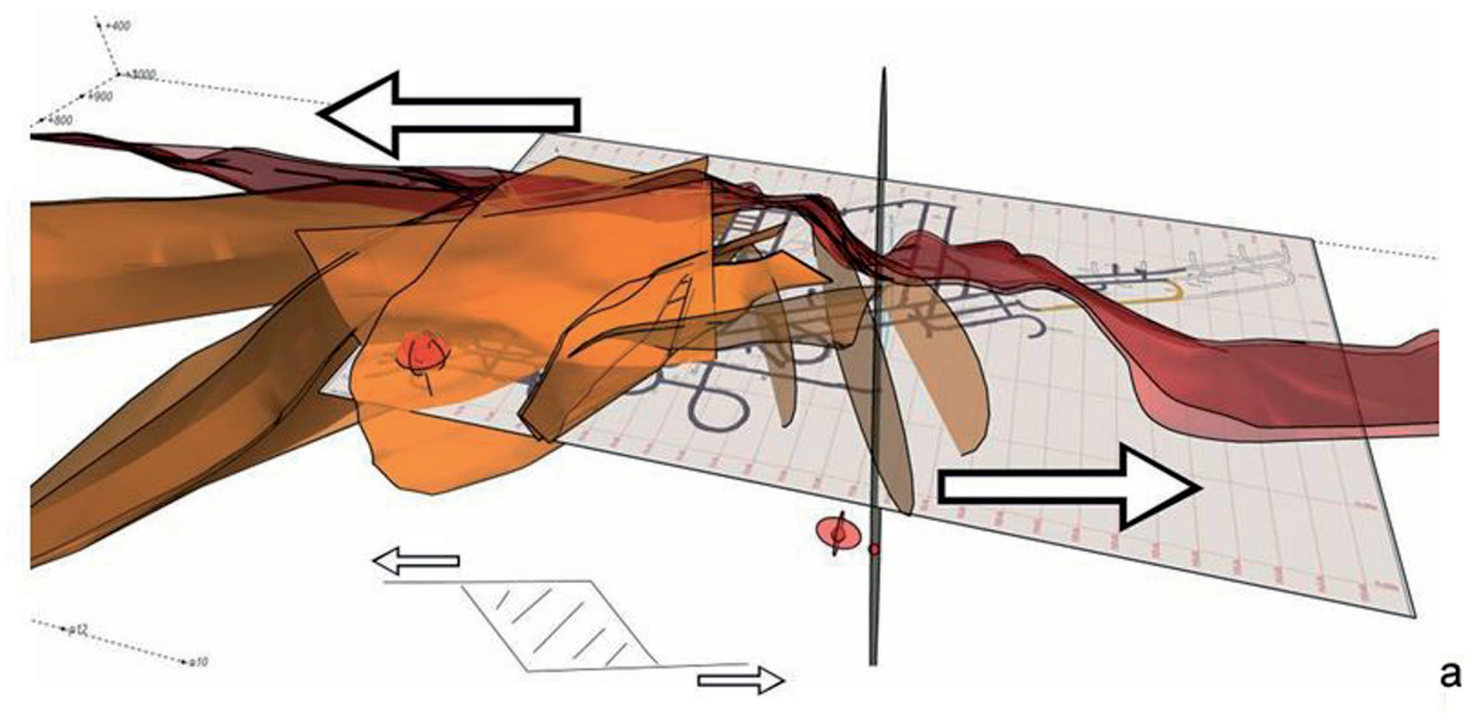

a

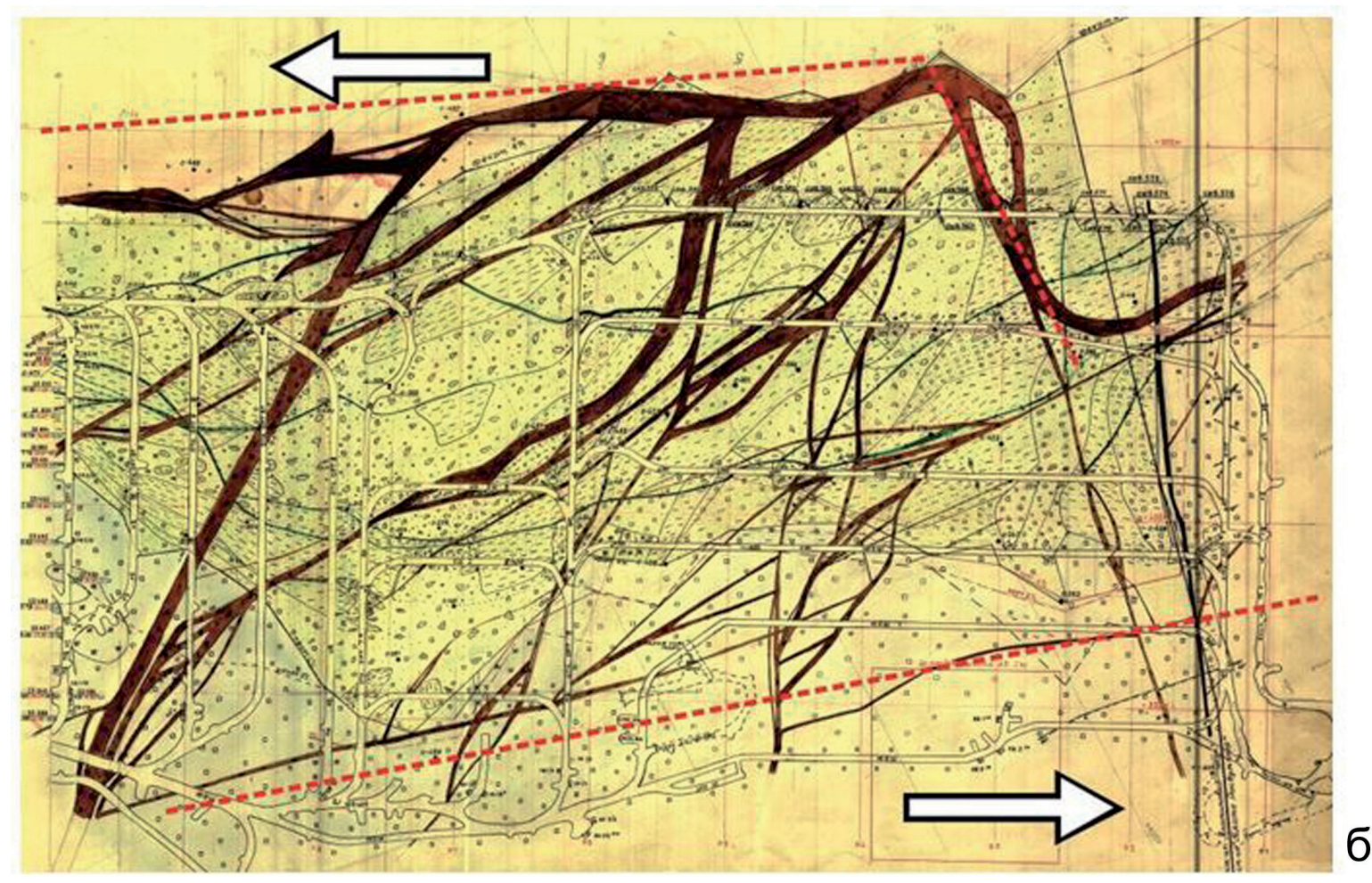

Рис. 2. Левосдвиговая зона в рудной зоне месторождения Апатитовый Цирк.

$\mathrm{a}$ - тримметрическая проекция разломной тектоники; б - геологический план с разломной тектоникой этого же месторождения.

Fig. 2. Left-lateral shear zone in the ore area of the Apatite Cirque deposit. $\mathrm{a}$ - trimetric projection of fault tectonics; $\mathrm{b}$ - geological plan with the fault tectonics of the same deposit.

Таким образом, для тектонической эволюции рудовмещающего фоидолитового комплекса Хибин характерны следующие стадии и деформации:

1. Стадия образования конического разлома в фойяитовой матрице в ходе образования кальдеры проседания. Кинематика сброса.

2. Инъецирование порций фоидолитового и щелочного расплавов по коническому разлому. Кинематика разрыва (гидроразрыва) и взброса. Следы магматического и пластического течений в направлениях от вертикального до полого-диагонального. 


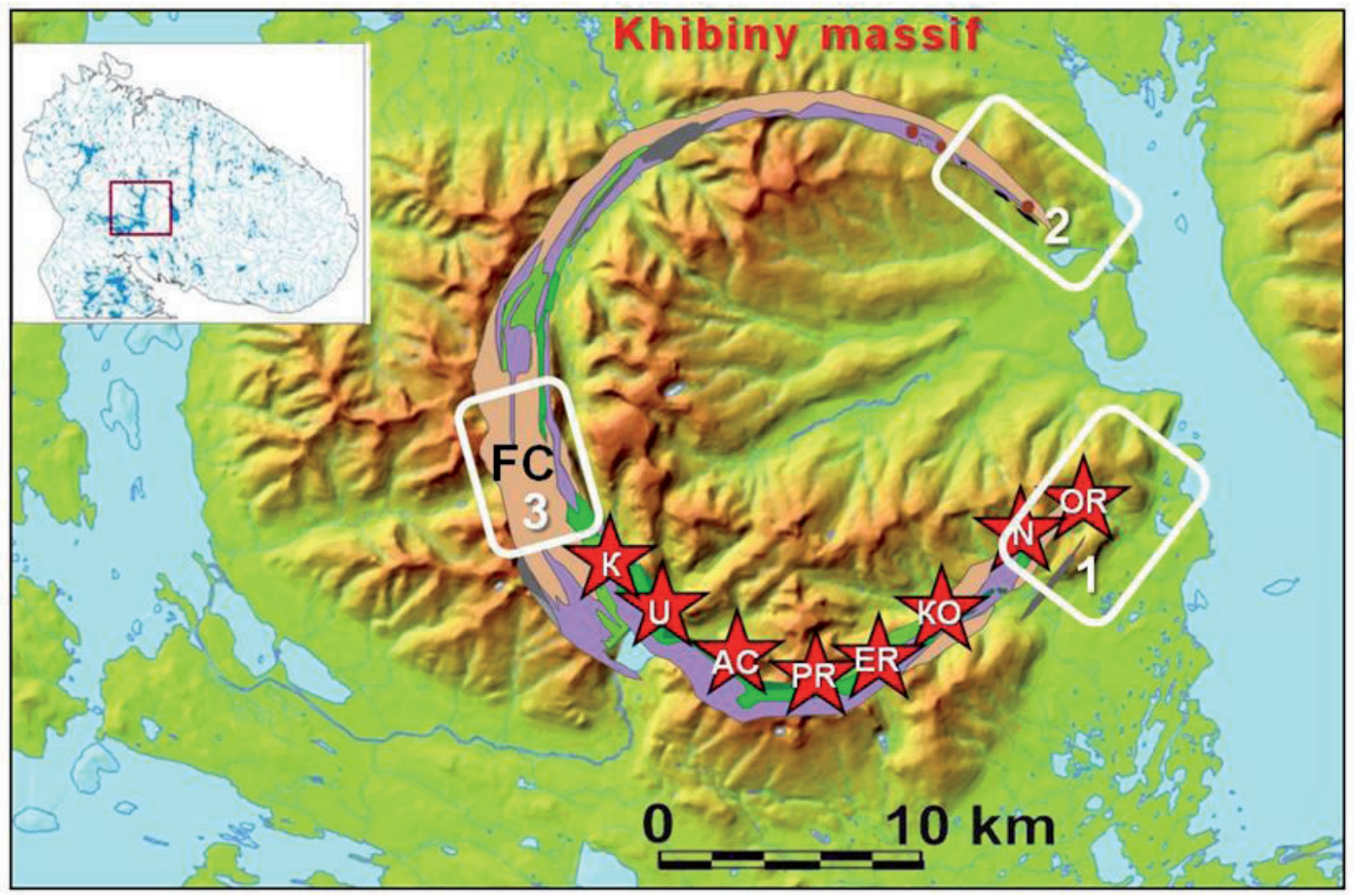

Рис. 3. Рекомендованные участки для поисков апатитовых руд в нетрадиционных обстановках: 1, 2 - офсетные руды; 3 - ремобилизованныех руды в структурных ловушках. FC - комплекс фоидолитов; красные звезды эксплуатирующиеся месторождения.

Fig. 3. Recommended areas for apatite ore prospecting in unconventional settings: 1, 2 - off-set ores; 3 - remobilized ores in structure traps. FC - foidolite complex; red asterisks - operating deposits.

3. Продолжение инъецирования остаточными дериватами и ремобилизованными расплавами / флюидами в ходе тектоно-магматической активизации, вызванной, вероятно, подъёмом консолидированной магматической колонны (осевой части плутона). Благодаря асимметричному её расположению (центр на востоке массива), центральный конус получает направление сдвигового субгоризонтального смещения примерно на запад, что повсеместно фиксируется в характере вязкопластических / реидных и хрупких деформаций. На данной стадии проявлено интенсивное брекчирование руд и вмещающих пород.

4. Продолжение подъёма колонны (возможно в циклично-реверсном режиме). Формирование левосдвиговых зон вдоль рудных тел и парагенезисов оперяющих сколовых и отрывных трещин (реидные и хрупкие деформации). Кинематика срывов и/или перемещений попеременно чередуется по типу взбросов и сдвигов (преимущественно левых для южной части ХМ). Высоко- и среднетемпературная гидротермальная проработка зон разломов.

5. Неотектоническая или голоценовая гляциоизостатическая активизация ХМ. Протрузивное воздымание всего массива со срывом его краевых частей и возможным захоронением части рудовмещающих толщ в месте первичного залегания (офсетные руды). Кинематика псевдо сбросов и взбросов. Интенсивное гипергенное воздействие с формированием вдоль разломов глинистодресвяных (гидрослюдистых) кор выветривания.

Эта интерпретационная схема отражает принципиальные черты тектоники фоидолитового комплекса и позволяет дополнить существующую прогнозно-поисковую модель, а также обосновать новые и нетрадиционные перспективные места локализации руд (рис. 3). Выделяются 3 участка, из которых 2 (юго-восточный и северо-восточный) перспективны на поиски офсетных залежей руд (Жиров, 2019; Zhirov, 2019) и 1 (западный) - на поиски ремобилизованных руд в структур- 
ных ловушках. Наиболее перспективной и тектонически обоснованной площадью является юговосточный фланг ФК, где мы имеем предпосылки для поисков апатитовых руд в двух нетрадиционных обстановках. Во-первых, офсетных руд в районе восточных склонов гор Суолуайв и Коашкар, а во-вторых, на глубоких горизонтах в направлении выклинивания фоидолитового комплекса, который, согласно реконструкциям имеет крутой угол погружения (ныряния) в СВ направлении. Укрупнённая прогнозная оценка потенциала только Суолуавского участка даёт прогнозные ресурсы порядка 75-95 млн. тонн руды со средним содержанием 13-15 \% $\mathrm{P}_{2} \mathrm{O}_{5}$ (Жиров, 2019). В целом для обсуждаемого нетрадиционного геолого-промышленного типа - руд в офсетном залегании прогнозные ресурсы можно оценить в 250-350 млн. т руды (40-50 млн. т $\mathrm{P}_{2} \mathrm{O}_{5}$ ).

Исследования выполняются в рамках плановой НИР № 0226-2019-0053.

\section{Литература}

1. Flinn D. 1965. On the symmetry principle and the deformation ellipsoid. Geol. Mag. V. 102. P. 36-45.

2. Zhirov D.V. Prospecting criteria for off-set apatite-nepheline deposits in the Khibiny massif area (NE Fennoscandian shield) / Conference Proceedings SGEM-2019, Albena (Bulgaria) 30 June -06 July 2019. Albena (Bulgaria). 2019. V. 19. Issue 1.3 Exploration and Mining. Mineral processing. P. 499-506. DOI 10.5593/sgem2019/1.3.

3. Zhirov D.V., Zhirova A.M. Neotectonics of the Khibiny alkaline massif / Conference Proceedings SGEM2018, Albena (Bulgaria) 30 June-09 July. 2018. Issue 1.1 Science and Technology in Geology. Exploration and Mining. P. 355-362.

4. Жиров Д.В. О перспективах обнаружения месторождений офсетных апатит-нефелиновых руд в районе Хибинского массива / Труды XVI Всероссийской (с международным участием) Ферсмановской научной сессии. Апатиты. 2019. С. 180-185. DOI 10.31241/FNS.2019.16.037.

5. Жиров Д.В., Маринин А.В., Жирова А.М., Сим Л.А. Неотектоника южной части Хибинского массива: результаты комплексной интерпретации «необычных» явлений / Труды Ферсмановской научной сессии ГИ КНЦ РАН. Апатиты. 2018. С. 140-143.

6. Жиров Д.В., Сим Л.А., Маринин А.В. Реконструкция палео стресс состояний в южной части Хибинского плутона (Восток Фенноскандинавского щита) / Труды Всероссийской научной конференции «Актуальные проблемы динамической геологии при исследовании платформенных областей» Москва. Геологический факультет МГУ им. М.В. Ломоносова. 24-26 мая 2016. М. Изд-во: «Перо», 2016. С. 39-44.

7. Каменев Е.А. Поиски, разведка и геолого-промышленная оценка апатитовых месторождений хибинского типа (Методические основы). Л. Изд-во: Недра. 1987. 188 с.

8. Маринин А.В., Сим Л.А., Жиров Д.В., Бондарь И.В. Структурные парагенезисы и тектонические напряжения южной части Хибинского массива / Труды Ферсмановской научной сессии ГИ КНЦ РАН, Апатиты. 2018. С. 239-241.

9. Методические рекомендации по применению Классификации запасов месторождений и прогнозных ресурсов твердых полезных ископаемых. Фосфатные руды. М. Изд-во: ГКЗ РФ. 2007. 41 с.

10. Онохин Ф.М. Особенности структуры Хибинского массива и апатито-нефелиновых месторождений. Л. Изд-во: Наука. 1975. 106 с.

11. Ребецкий Ю.Л. Тектонические напряжения и прочность природных горных массивов. М.Изд-во: ИКЦ Академкнига. 2007. 406 с.

12. Сим Л.А. Изучение тектонических напряжений по геологическим индикаторам (методы, результаты, рекомендации) // Изв. ВУЗов. Геология и разведка. 1991. № 10. С. 3-22. 